\title{
THE ANALYSIS OF SOIL RESISTANCE DURING SCREW DISPLACEMENT PILE INSTALLATION
}

\author{
ADAM KRASIŃSKI \\ Gdańsk University of Technology, Department of Geotechnics, Geology and Maritime Engineering, \\ ul. Narutowicza 11/12, 80-233 Gdańsk, Poland, e-mail: akra@pg.gda.pl
}

\begin{abstract}
The application of screw displacement piles (SDP) is still increasing due to their high efficiency and many advantages. However, one technological problem is a serious disadvantage of those piles. It relates to the generation of very high soil resistance during screw auger penetration, especially when piles are installed in non-cohesive soils. In many situations this problem causes difficulties in creating piles of designed length and diameter. It is necessary to find a proper method for prediction of soil resistance during screw pile installation. The analysis of screw resistances based on model and field tests is presented in the paper. The investigations were carried out as part of research project, financed by the Polish Ministry of Science and Higher Education. As a result of tests and analyses the empirical method for prediction of rotation resistance (torque) during screw auger penetration in non-cohesive subsoil based on CPT is proposed.
\end{abstract}

Key words: screw displacement pile, pile installation, pile auger, torque, soil resistance

\section{INTRODUCTION}

During the installation of SDP pile, when the auger penetrates the non-cohesive subsoil, high soil resistance is observed. This screw resistance is one of the biggest problems of SDP pile technology and is a subject of ongoing scientific investigations and analyses. It was also the reason that many types of screw auger have already been introduced into practice. It is believed that soil resistance could be reduced by appropriate auger construction. Due to the difficulties connected with the installation of screw displacement piles in various types of soil conditions, these piles are often omitted in geotechnical projects.

High soil resistance during screw auger penetration means the high value of torque $\left(M_{T}\right)$, which should be applied to rotate the auger. Therefore, very massive drilling machines with high torque (at least $200 \mathrm{kNm}$ ) need to be used for screw displacement pile installation. The analysis of installation effort connected with SDP piles was carried out, among others, by NeSmith [10].

The problem is additionally complicated due to the fact that high soil resistances during the installation not always mean the high bearing capacity of screw pile. The analogy to driven piles, where the high blowing resistances indicate the high pile bearing capacity, cannot be taken in the case of SDP piles. This results from the fact that the load bearing capacity of screw displacement piles is primarily based on the shaft resistance $Q_{s}$, [4-6].

Learning from practice shows that we rather will not be able to reduce significantly the soil resistances by changing the shape or the construction of screw auger. The only way to solve the problem seems to identify the phenomena occurring in the soil during the screwing process and to propose a method for predicting the soil resistances.

This paper presents the results of the author's own model and field tests as well as theoretical analyses concerning soil resistances during screw auger penetration in non-cohesive soil. Model and field tests were correlated with CPT tests. Thanks to these results, the empirical method of screw torque $M_{T}$ value prediction based on CPT tests has been developed and presented.

\section{DESCRIPTION OF SCREW AUGER PENETRATION PROCESS}

The main task of screw pile auger is to create a hole in the ground by radial soil displacement and to fill the hole with the concrete. Bottom part of the 
auger is helical but in the upper part the diameter of auger core gradually increases. Thanks to its shape the auger penetrates the soil during rotation and displaces the soil radially. Sometimes, a vertical compressive force is added from drilling machine to initiate the auger penetration. In other cases a tension force is used to decrease the penetration velocity and to reduce the torque value.

Screwing process initiates a significant increase of radial stresses in the surrounding soil. These stresses are the main reason of high soil friction around the auger surface. There are also soil resistances under the auger base.

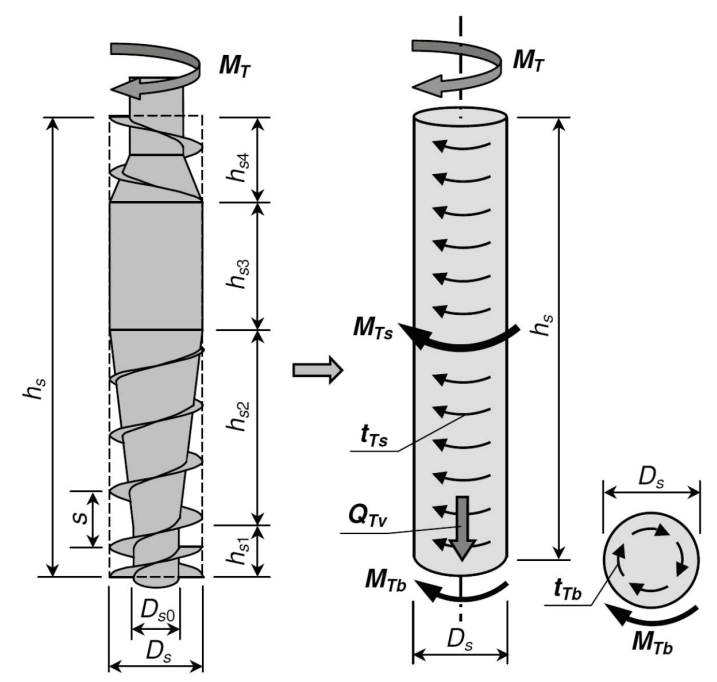

Fig. 1. Simplified scheme of SDP auger taken for analysis
The insertion of a drilling tool into the ground is a complex process, difficult to theoretical describe. Therefore, a simplified scheme of the auger was taken for analysis. In this scheme, presented in Fig. 1, the real auger is represented by the equivalent cylinder.

It is assumed that the total value of torque $M_{T}$ consists of two components: $M_{T S}$ and $M_{T b}$

$$
M_{T}=M_{T s}+M_{T b} .
$$

$M_{T s}$ is connected with soil friction $t_{T s}$ around the auger shaft and is generated by the auger rotation. $M_{T b}$ is connected with soil unit friction $t_{T b}$ under the auger base and is generated by the rotation and auger vertical movement. Components $M_{T s}$ and $M_{T b}$ are defined by the formulas

$$
\begin{gathered}
M_{T s}=\frac{\pi \cdot D_{s}^{2}}{2} \cdot \sum t_{T s ; i} \cdot h_{s ; i}, \\
M_{T b}=\frac{\pi \cdot D_{s}^{3}}{12} \cdot t_{T b} .
\end{gathered}
$$

Screw resistance is also defined by the number of auger rotations $n_{T}$ per unit depth of penetration. In the author's opinion $M_{T}$ and $n_{T}$ are the most important parameters of SDP pile installation. In practice, in the reports of screw displacement pile installation there is given the information about: oil pressure in the hydraulic rotary tool, rotation velocity RPM (rotation per minute) and penetration velocity (meters per hour). $M_{T}$ and $n_{T}$ values are obtained from recalculating the

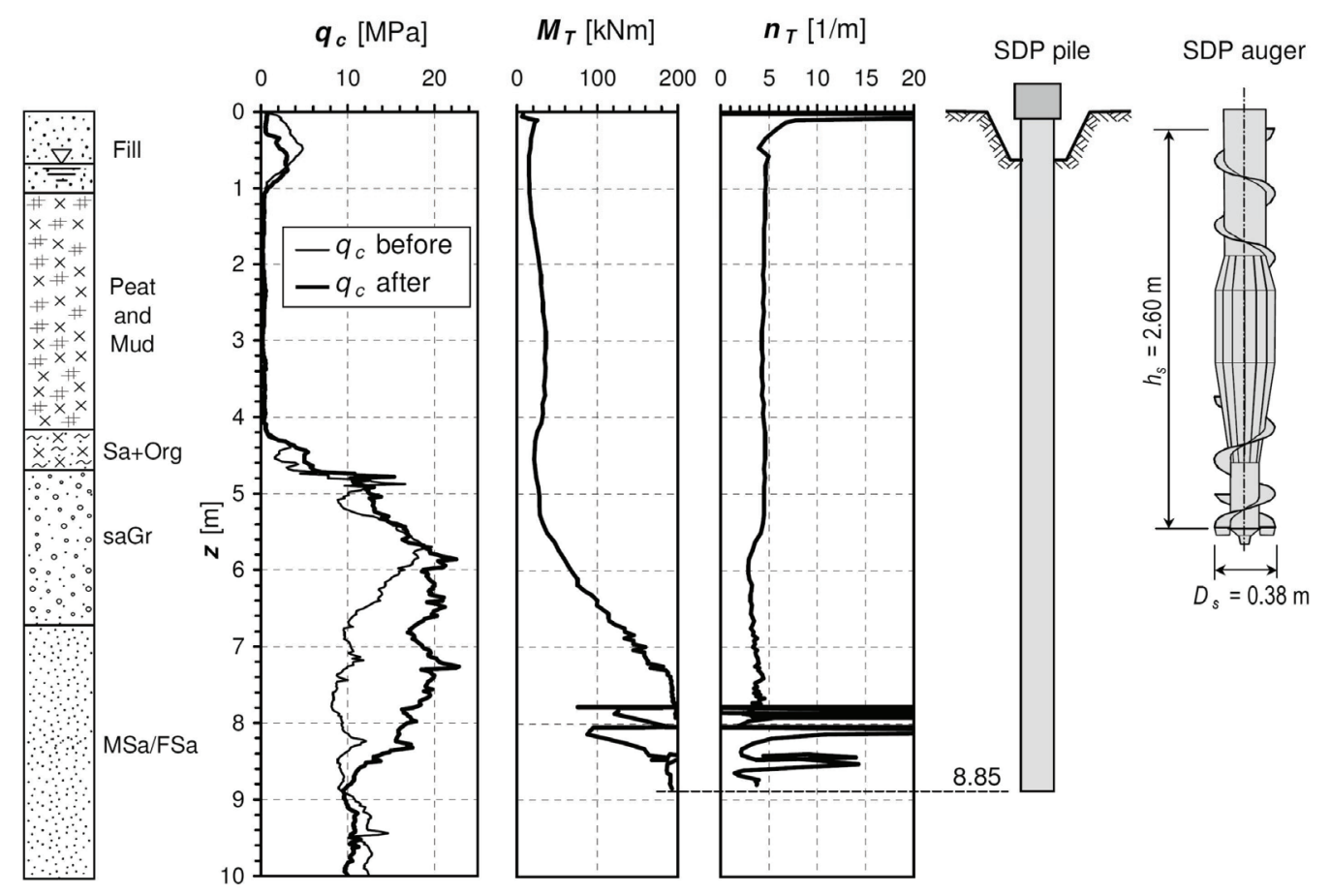

Fig. 2. Test and measurement results concerning example of SDP pile, [6] 
three parameters mentioned. In most drilling machines, the value of torque $M_{T}$ depends on hydraulic oil pressure and on RPM (the smaller the RPM, the higher the $M_{T}$ for a given oil pressure).

Figure 2 presents the example of measurement results concerning SDP pile installation in correlation with CPT test of subsoil. CPT was carried out before and after pile installation. The pile was installed by drilling machine of maximal torque $M_{T}=200 \mathrm{kNm}$ and by the auger of shape presented in the figure.

In the CPT diagram one may note that after pile installation there is an increase of $q_{c}$ resistances in the region around the pile shaft, but under the pile base that increase is not very high. Similar phenomenon was observed with regard to the other SDP piles tested. This allowed us to conclude that screw displacement piles affect the soil conditions (density and stress level) mainly around their shafts.

In the $M_{T}$ and $n_{T}$ diagrams one may notice that during auger penetration into the bearing stratum an intensive increase of torque is observed with constant value of the rotation number $n_{T}$ (about 4 rotations per meter). When the torque reached the maximal value of $200 \mathrm{kNm}$, at the depth of $7.5 \mathrm{~m}$ under the ground level, the penetration velocity was reduced. As a result, the $n_{T}$ value increased whereas the $M_{T}$ value decreased. Thanks to such actions it was possible to create a pile of length $L=8.85 \mathrm{~m}$. This example shows that the torque value can be influenced by regulation of auger penetration velocity, thus by rotation number $n_{T}$.

\section{MODEL TESTS}

Model tests were conducted using SDP auger models prepared in 1:7.5 scale in two diameters (Fig. 3). Auger model SDP1 represents the original auger of $400 \mathrm{~mm}$ in diameter, while model SDP2 represents the original auger of $500 \mathrm{~mm}$ in diameter. The experiments were carried out at the Geotechnical Laboratory in Gdańsk University of Technology. The research device consists of steel container $(2.0 \mathrm{~m}$ diameter and $2.0 \mathrm{~m}$ high) for soil. Moist fine sand was prepared with appropriate density achieved by vibration and controlled by CPT tests.

The augers were screwed into the soil using hand operated device and vertical load of constant value of $0.5 \mathrm{kN}$. Soil resistances during screwing were measured in terms of torque $M_{T}$ and number of rotations $n_{T}$ per each $0.1 \mathrm{~m}$ of auger penetration. Several series of tests were carried out. Apart from the measurements of soil resistances during auger penetration also the SDP and "Atlas" pile models were installed and tested in respect of their bearing capacity. A detailed description of pile model tests is presented also in other author's work [3].

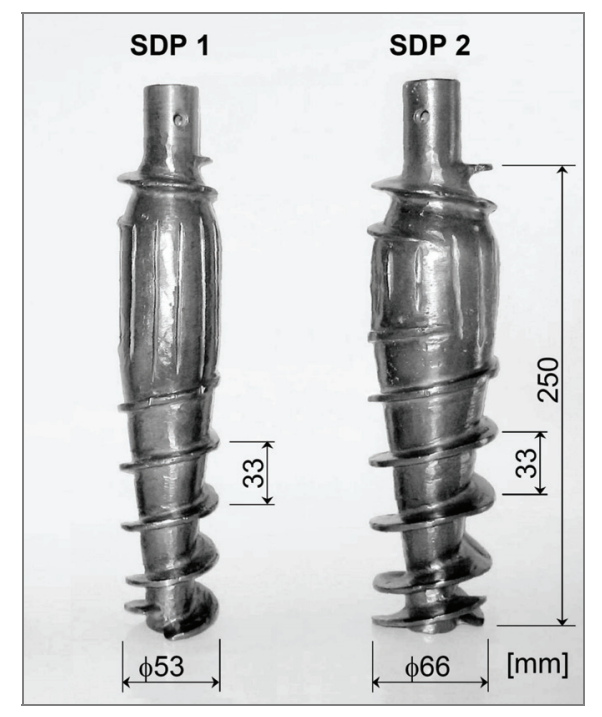

Fig. 3. Models of SDP augers (model scale 1:7.5)

During screw auger penetration usually only the total value of torque $M_{T}$ is measured, and it is difficult to divide its value into $M_{T S}$ and $M_{T b}$ components. Therefore, in one of the tests the measuring of screwing resistances was performed in a special way. It was assumed that if the auger vertical penetration was blocked, then during rotation only the $M_{T s}$ component was measured. Before blocking the total $M_{T}$ value was measured. $M_{T b}$ component was then calculated as a difference between $M_{T}$ and $M_{T s}$. During the test, which is shown in Fig. 4, also the value of vertical force $Q_{T v}$ was measured. The author named this tension force as "auger thrust". The measurements of $M_{T}, M_{T s}$ and $Q_{T v}$ were carried out every $0.1 \mathrm{~m}$ of penetration from $0.5 \mathrm{~m}$ to $1.0 \mathrm{~m}$ of depth.

The results of measurements, which were done for both augers SDP1 and SDP2, are presented as the diagrams in Fig. 5, together with diagrams of cone resistances $q_{c}$ and rotation numbers $n_{T}$.

Next, using the auger scheme presented in Fig. 1, the values of unit soil resistances $t_{T s}$ and $t_{T b}$ were calculated and presented in Fig. 6 as diagrams together with diagrams of ratios $t_{T s} / q_{c s}$ and $t_{T b} / q_{c b}$. The $q_{c s}$ value was taken as an average $q_{c}$ from the auger length $h_{s}$, whereas $q_{c b}$ was taken as an average $q_{c}$ of $-D_{s}$ to $+D_{s}$ region around the auger base level. 

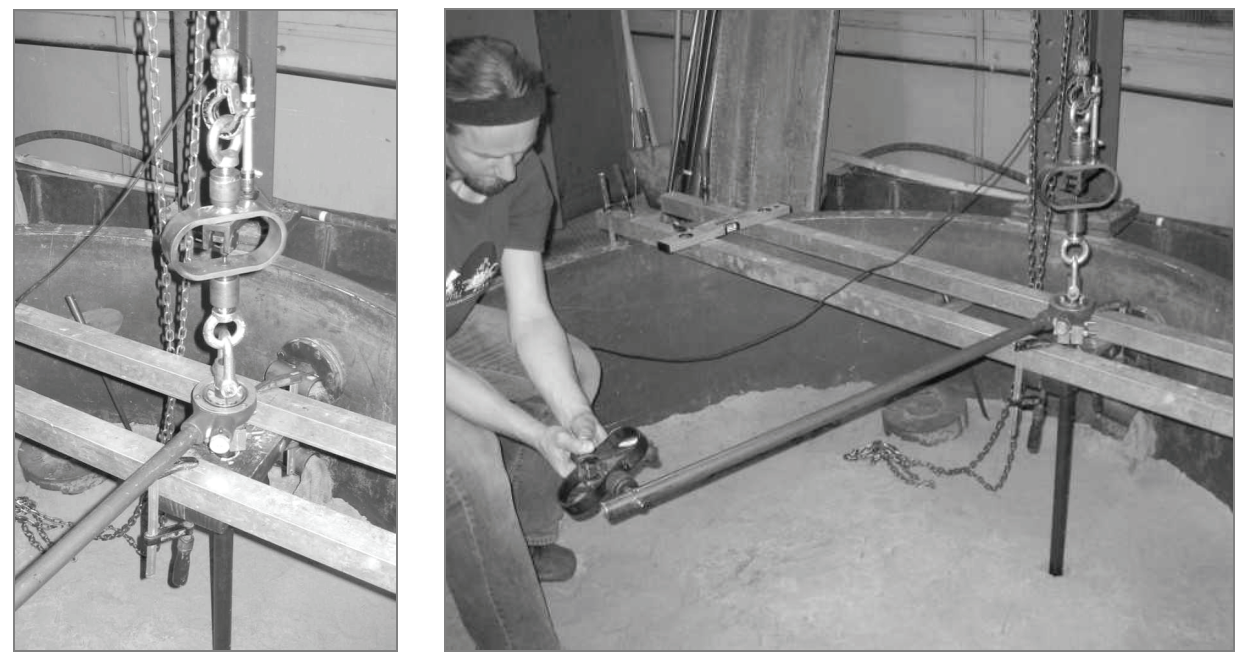

Fig. 4. Measurement of torque component $M_{T s}$ and auger thrust $Q_{T v}$ in model test
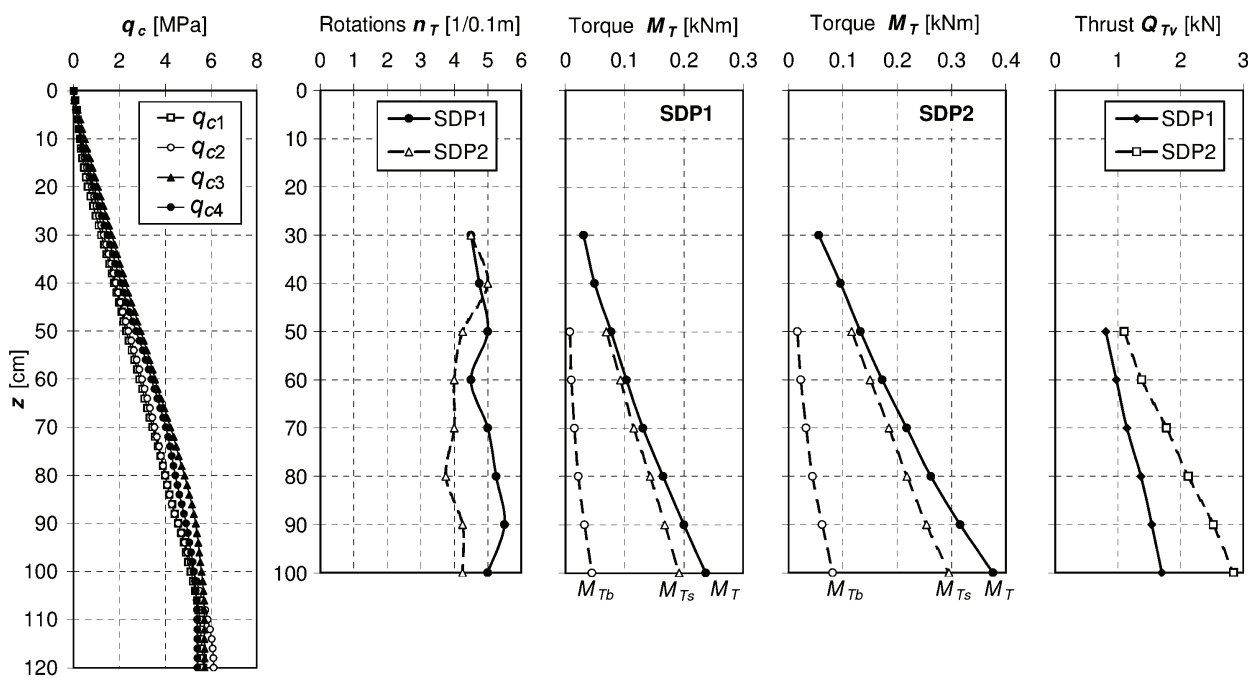

Fig. 5. The results of auger SDP screwing tests with measurements of torques $M_{T}, M_{T s}, M_{T b}$ and force $Q_{T v}$
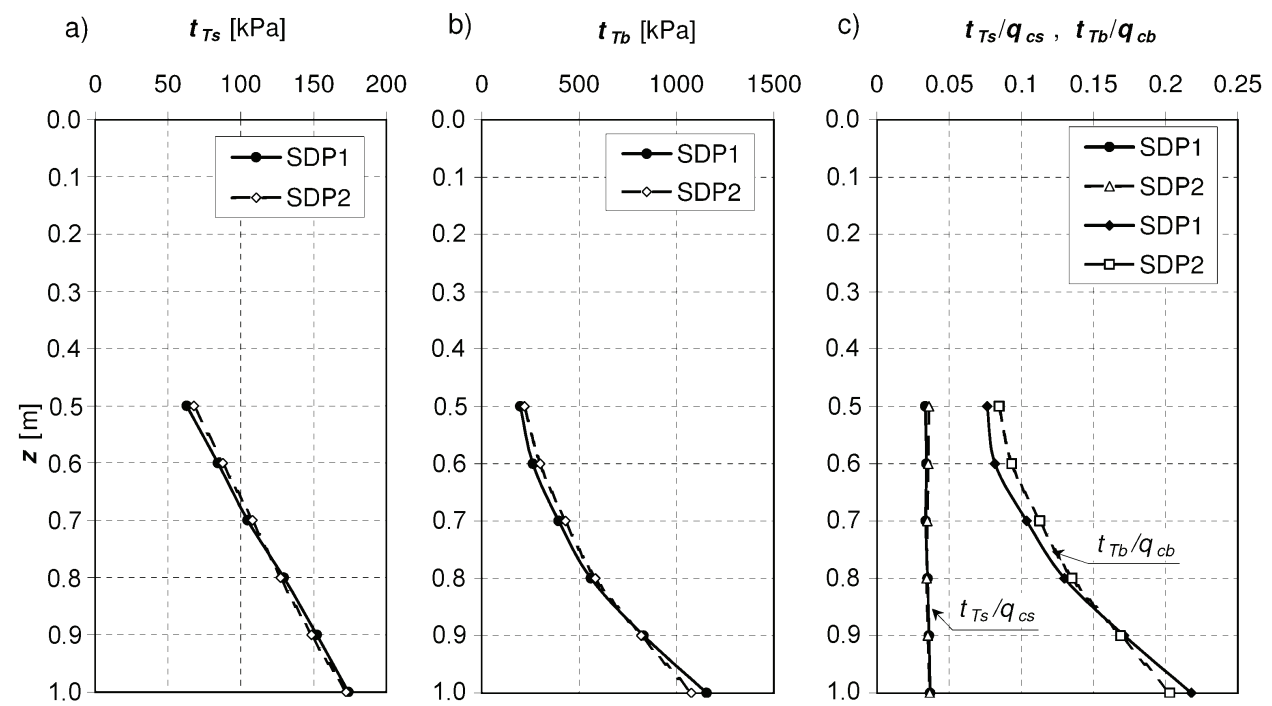

Fig. 6. Unit friction resistances $t_{T s}$ and $t_{T b}$ and their relations to cone resistances $q_{c}$ 
It can be noted that ratio $t_{T S} / q_{c s}$ is constant along the whole depth, which means that unit resistance $t_{T S}$ is proportional to cone resistance $q_{c}$. On this basis the following relation is created

$$
t_{T s}=0.035 \cdot q_{c s} .
$$

The ratio $t_{T b} / q_{c b}$ is not constant but is increasing with depth. It was assumed that this increase is caused by auger thrust $Q_{T v}$. The mechanism of auger thrust initiation can be explained by analogy to ordinary screw. In such a screw, when the friction on the thread is neglected, a relation between $M_{T s}$ component of torque and thrust $Q_{T v}$ results from the principle of energy conservation. In the case of auger which is penetrated into the soil the following relation is assumed

$$
Q_{T v}=a \cdot \frac{2 \pi \cdot M_{T s}}{n_{T} \cdot s}
$$

where

$s$ - pitch of the auger helix,

$a$ - reduction factor, taking into account the losses caused by the soil friction and by the fact that vertical velocity of auger insertion is less than it would result from pitch of helix $s(a<1.0$, the exact value of $a$ is not known).

The number of auger rotation per $1.0 \mathrm{~m}\left(n_{T}\right)$ should be taken into account as a value without units.

The thrust $Q_{T v}$ causes the auger base impact on the soil by vertical pressure $q_{T b}$ which can be expressed by the formula

$$
q_{T b}=\frac{4 Q_{T v}}{\pi D_{s}^{2}}=8 a \cdot \frac{M_{T s}}{n_{T} \cdot s \cdot D_{s}^{2}} .
$$

The vertical pressure $q_{T b}$ influences directly the soil friction $t_{T b}$ under the auger base. The following relation is assumed

$$
t_{T b}=q_{T b} \cdot \mu_{T b}
$$

where $\mu_{T b}$ - friction coefficient of the soil under the auger base.

On the basis of model test results it was concluded that the value $\mu_{T b}$ is not constant but increases with depth approximately proportionally to the increase of cone resistance $q_{c}$. The following relation is assumed

$$
\mu_{T b}=b \cdot \frac{q_{c b}}{p_{\text {ref }}},
$$

where

$$
\begin{aligned}
& p_{\text {ref }}=1.0 \mathrm{MPa}-\text { reference stress, } \\
& b-\text { conversion factor (not known). }
\end{aligned}
$$

Equation (7) takes the form

$$
t_{T b}=8 a \cdot \frac{M_{T s}}{n_{T} \cdot s \cdot D_{s}^{2}} \cdot b \cdot \frac{q_{c b}}{p_{r e f}} .
$$

After introducing two new coefficients

$$
m_{T s}=\frac{M_{T s}}{s \cdot D_{s}^{2} \cdot p_{\text {ref }}}
$$

and

$$
m_{T b}=8 \cdot a \cdot b
$$

we receive a new form of equation (9)

$$
t_{T b}=\frac{1}{n_{T}} \cdot m_{T s} \cdot m_{T b} \cdot q_{c b} .
$$

The coefficient $m_{T b}$ was determined experimentally from test results by using back analysis method. It was not necessary to determine values of $a$ and $b$ coefficients separately. The $m_{T b}$ value was found to be about 4.40 and was approximately constant in relation to depth and similar in the case of both augers SDP1 and SDP2.

Finally, from the analysis one can obtain empirical equations for the calculation of torque components $M_{T S}$ and $M_{T b}$ and total torque $M_{T}$ of screw displacement augers on the basis of cone resistances $q_{c}$. Moreover, the analysis has shown that $M_{T S}$ component depends mainly on the cone resistance $q_{c}$, whereas $M_{T b}$ component depends on $M_{T s}$ value, cone resistance and number of auger rotations per unit depth $n_{T}$.

\section{FIELD TESTS}

A method for prediction of soil resistance during screw auger penetration was prepared also for piles in natural scale. This method concerns SDP and CMC (Controlled Modulus Column) augers. There were applied the same assumptions and very similar equations as in the model test analyses, but several additional factors and effects had to be taken into account. These factors concerned the auger shape, nonhomogeneity of soil profile and stress level in the subsoil.

The same scheme of auger as presented in Fig. 1 and the same equations (1)-(3) of $M_{T}, M_{T s}$ and $M_{T b}$ calculations were applied.

After many trial replications of torque values measured in the field tests, the following formulas for $t_{T S}$ and $t_{T b}$ resistances were determined 

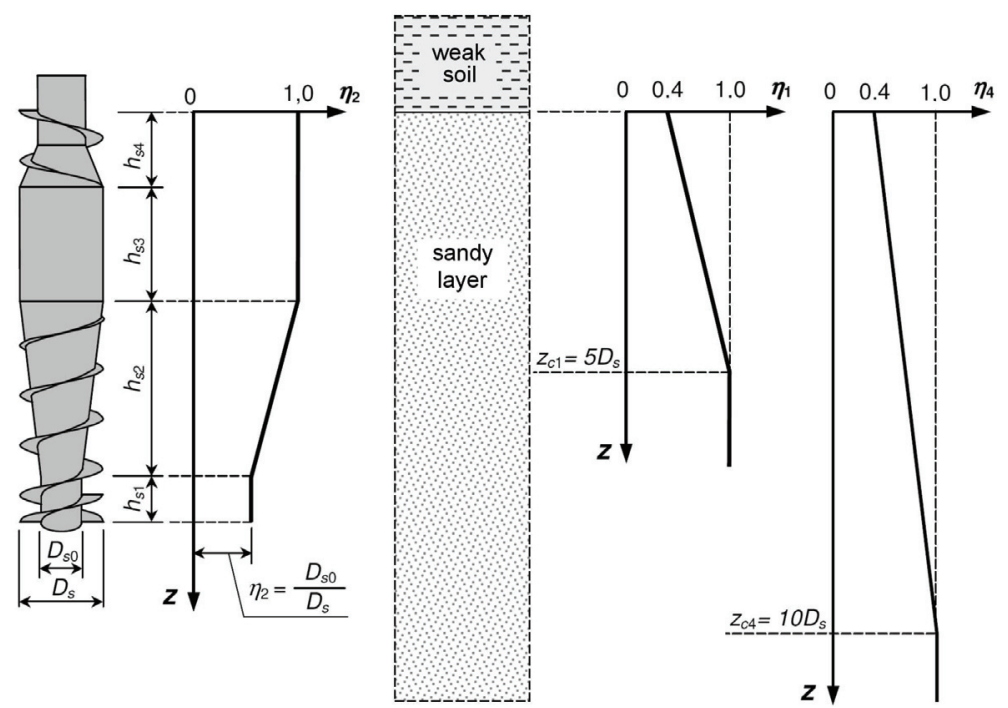

Fig. 7. Diagrams for determination of $\eta_{1}, \eta_{2}$ and $\eta_{4}$ coefficients

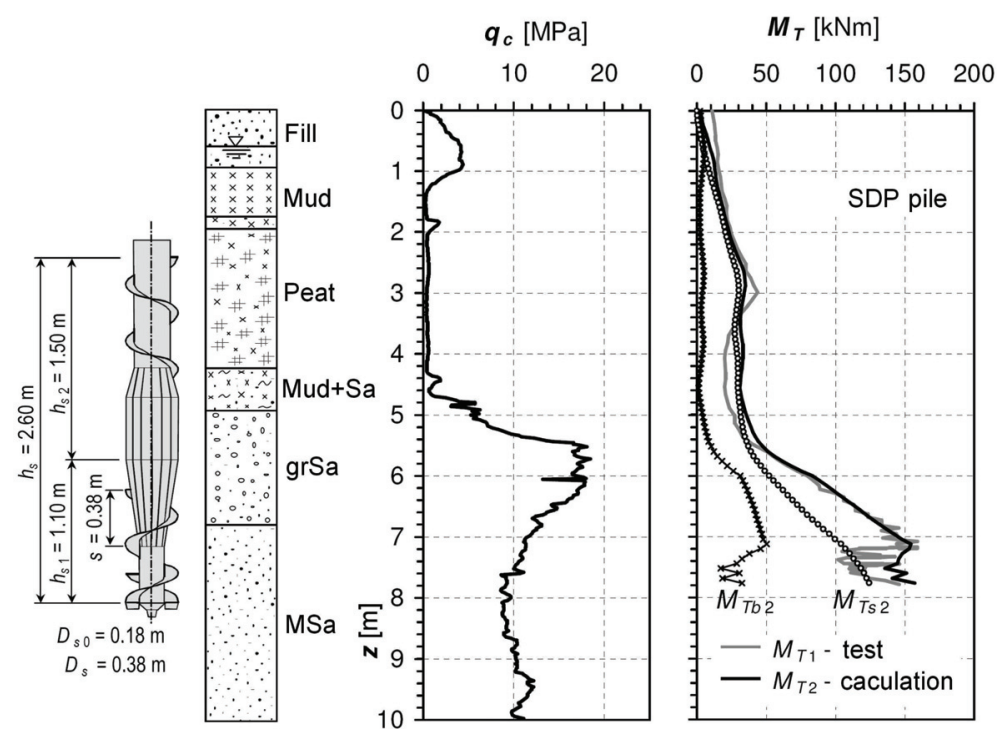

Fig. 8. Torque $M_{T}$ prediction for the SDP pile installation on the field site

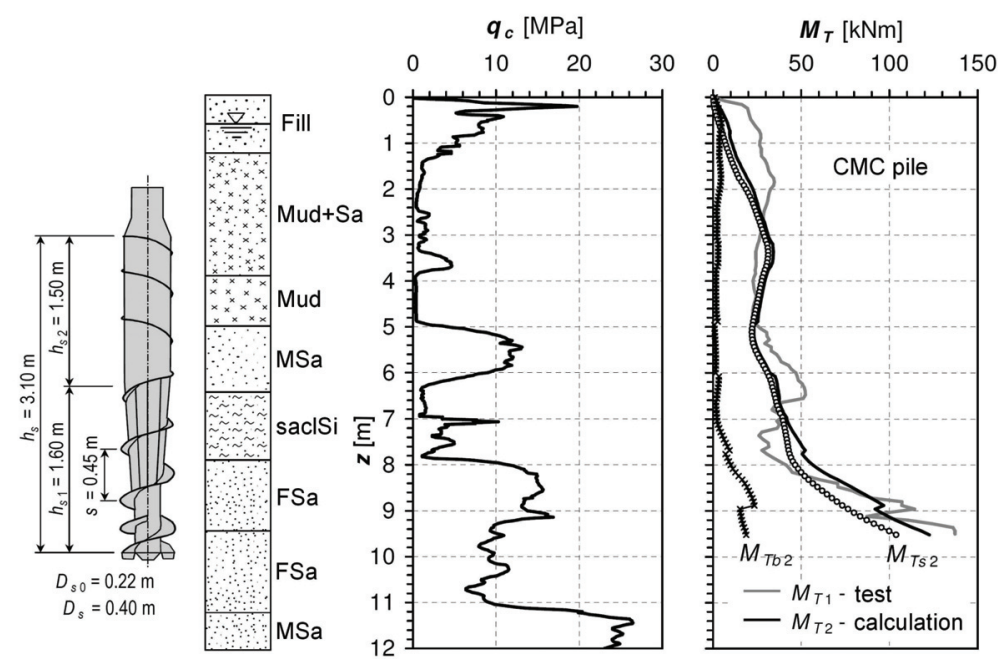

Fig. 9. Torque $M_{T}$ prediction for the CMC pile installation on the field site 


$$
\begin{array}{ll}
t_{T s}=0.035 \cdot \eta_{1} \cdot \eta_{2} \cdot \eta_{3} \cdot q_{c s} & {[\mathrm{kPa}],} \\
t_{T b}=1.2 \cdot \eta_{3} \cdot \eta_{4} \cdot m_{T s} \cdot \frac{q_{c b}}{n_{T}} & {[\mathrm{kPa}],}
\end{array}
$$

where

$\eta_{1}, \eta_{4}$ - coefficients dependent on the depth of auger penetration in bearing soil layer,

$\eta_{2}$ - coefficient of auger shape influence,

$\eta_{3}$ - coefficient of stress level in the subsoil.

Coefficients $\eta_{1}, \eta_{2}$ and $\eta_{4}$ are read from diagrams presented in Fig. 7, whereas $\eta_{3}$ coefficient is calculated from the formula

$$
\eta_{3}=\frac{\sigma_{v 0}^{\prime}}{100 \mathrm{kPa}}
$$

where $\sigma_{v 0}^{\prime}$ is a vertical effective stress in the subsoil.

The value of $m_{T s}$ coefficient is calculated using formula (10).

The number of auger rotations per unit depth $n_{T}$ which has to be applied in equation (14) is unknown and we must assume its value. It was mentioned earlier that the $n_{T}$ value can be controlled during screwing process by the piling machine operator. In the calculation we should take the planned or maximal accepted value of $n_{T}$ (usually no more than 20 to 40 rotations per meter).

\subsection{COMPARISON OF PREDICTED AND MEASURED SCREW RESISTANCES}

Figures 8 and 9 present the results of calculated replications of real screw resistances measured during the installation of two selected piles in the field. Particular emphasis was placed on $M_{T}$ value prediction in the bottom part of subsoil when the auger was penetrated in the bearing sandy layer. The organic soils in the upper parts of subsoil were less important, then the screw resistances in these layers were taken approximately as: $t_{T s}=f_{s}$ and $t_{T b}=5 \cdot f_{s}$, where $f_{s}$ is the sleeve friction measured in CPT test. The values of $\eta_{1}, \eta_{2}, \eta_{3}$ and $\eta_{4}$ coefficients were taken as equal to 1.0 in organic soil. The values of $n_{T}$ were taken as equal to those read from the pile installation reports.

On the basis of diagrams presented in Figs. 8 and 9 it can be concluded that the proposed method for prediction of soil resistance during SDP and CMC auger penetration in non-cohesive soils provides good results.

\section{CONCLUSIONS}

The tests and analyses presented in the paper showed that rotation resistances during screw displacement auger penetration in non-cohesive soils depend on soil strength properties (expressed by CPT cone resistances $q_{c}$ ), auger geometry and screw technique (the velocity of rotation and penetration). The total value of torque $M_{T}$ generated by screwing process can be divided into two components: $M_{T S}-$ moment resulting from soil friction around the auger shaft and $M_{T b}$ - moment resulting from soil resistances under the auger base.

The calculation method developed as a result of tests and analyses allows us to predict the rotation resistances (a value of torque $M_{T}$ ) during SDP auger penetration into non-cohesive subsoil on the basis of CPT results. The method was verified positively with several practical examples of SDP and CMC pile installation in the field. On the base of it, we will be able to know what energy of piling machine is required to install the designed screw displacement pile. This prediction method can be applied to design screw displacement piles together with the author's own method for pile bearing capacity calculation [7] or with other calculation methods, proposed, for example, by Bustamante and Gianeselli [1], [2], Maertens and Huybrechts [8] or by NeSmith [9].

It should be underlined that many elements of the calculation method proposed were assumed in a simplified way. Due to this fact it may not work well in every case. This method should rather be considered as a preliminary proposal, which require many tests and verifications and will certainly be subjected to modifications.

\section{REFERENCES}

[1] Bustamante M., Gianeselli L., Design of auger displacement piles from in situ tests, Proceedings of International Geotechnical Seminar on Deep Foundations on Bored and Auger Piles, BAP II, Balkema, Rotterdam 1993, pp. 21-34.

[2] Bustamante M., Gianeselli L., Installation parameters and capacity of screwed piles, Proceedings of International Geotechnical Seminar on Deep Foundations on Bored and Auger Piles, BAP III, Balkema, Rotterdam 1998, pp. 95-108.

[3] KRASIŃSKI A., Model tests of screwed piles, Proc. of the XIV Danube-European Conf. on Geotechnical Engineering, Bratislava, Slovak Republic, June 2-4, 2010, 237+CD.

[4] KRAsińsKi A., Field tests of screw displacement piles and columns SDP and SDC, Drogi i Mosty, 2011a, No. 1-2, pp. 21-58 (in Polish). 
[5] KRASIŃSKI A., Results of field tests of screw displacement pile and columns, Inżynieria Morska i Geotechnika, 2011b, No. 6, pp. 510-530 (in Polish).

[6] KRASIŃSKI A., Bearing capacity and interaction with soil of screw displacement piles, Final report of research project No. N N506 432936 for the Polish Ministry of Science and Higher Education, Gdansk (in Polish, not published), 2011c.

[7] KRASIŃSKI A., Proposal for calculating the bearing capacity of screw displacement piles in non-cohesive soils based on CPT results, Studia Geotechnica et Mechanica, 2012, Vol. XXXIV, No. 4, pp. 41-51.
[8] Maertens J., HuyBrechts N., Belgian screw pile technology. Design and recent developments, Swets \& Zeitlinger B.V., Lisse, The Netherlands, 2003, p. 372.

[9] NeSmith W.M., Static capacity analysis of augered, pressure-injected displacement piles, Proc. of the Int. Deep Foundation Congress 2002, Geotechnical Special Publication, 2002, No. 116, Vol. 2, ASCE, pp. 1174-1186.

[10] NESMITH W.M., Installation effort as an indicator of displacement screw pile capacity, Deep Foundation on Bored and Auger Piles, BAP IV, Van Impe (ed.), Millpress, Rotterdam 2003, pp. 177-181. 